\title{
MENINGKATKAN KEMAMPUAN MENULIS PUISI MELALUI METODE IMITASI PADA SISWA KELAS VI SDN 2 LIMBOTO KABUPATEN GORONTALO
}

\author{
Dewi Harun \\ Guru SDN 2 Limboto Kecamatan Limboto Kabupaten Gorontalo Provinsi Gorontalo \\ Dewiharun74@gmail.com
}

\begin{abstract}
Writing poetry is one of the activities at school which is included in literacy activities. Literacy activities can enrich students' knowledge and insight, especially in writing poetry. In order for students to be able to write poetry properly and correctly, it is necessary for the creativity of a teacher to create a learning innovation that can motivate students' enthusiasm for learning, knowledge and skills. The teacher must be able to innovate in learning so as to create meaningful learning for students and one of the innovations chosen is the selection of methods in learning. The purpose of this study is to describe the results of learning innovation using imitation methods. The data generated in the first cycle of 33 the number of grade VI students who are able to make poems properly are only $0.39 \%$ and those who have not been able to make poems properly and correctly by $0.60 \%$ with both percentages of $0.21 \%$. From the results of the first cycle, revisions were made for the implementation of the second cycle, so that in the second cycle learning an increase of $0.85 \%$ of students was able to make poetry well and correctly, while students who were unable to $0.15 \%$ with a percentage of 0.70 $\%$ The percentage increase between cycles I to II was 0.49\%. So it is concluded that the imitation method is very good for use in language learning, especially poetry writing material.
\end{abstract}

Keywords: Imitation Method, Poetry Writing Ability

\begin{abstract}
Abstrak
Menulis puisi merupakan salah satu kegiatan disekolah yang termasuk dalam kegiatan literasi. Kegiatan literasi dapat memperkaya pengetahuan dan wawasan siswa terutama dalam menulis puisi. Agar siswa mampu menulis puisi dengan baik dan benar maka perlu kreativitas seorang guru dalam menciptakan sebuah inovasi pembelajaran yang dapat memotivasi semangat belajar, pengetahuan dan keterampilan siswa. Guru harus mampu melakukan inovasi dalam pembelajaran sehingga dapat tercipta pembelajaran yang bermakna bagi siswa dan salah satu inovasi yang dipilih adalah pemilihan metode dalam pembelajaran. Tujuan penelitian ini adalah mendeskripsikan hasil inovasi pembelajaran dengan menggunakan metode imitasi. Data yang di hasilkan pada siklus I dari 33 jumlah siswa kelas VI yang mampu membuat puisi dengan baik dan benar hanya sebesar $0,39 \%$ dan yang belum mampu membuat puisi dengan baik dan benar sebesar $0,60 \%$ dengan prosentase keduanya sebesar $0,21 \%$. Dari hasil siklus I ini di lakukan revisi perbaikan untuk pelaksanaan siklus II, sehingga pada pembelajaran siklus II terjadi peningkatan sebesar 0,85\% siswa telah mampu membuat puisi dengan baik dan benar, sedangkan siswa yang belum mampu $0,15 \%$ dengan prosentase $0,70 \%$. Prosentase peningkatan antara siklus I ke II sebesar 0,49\%. Sehingga di simpulkan bahwa metode imitasi sangat baik untuk di gunakan dalam pembelajaran bahasa khususnya materi menulis puisi.
\end{abstract}

Kata Kunci: Metode Imitasi, Kemampuan Menulis Puisi 


\section{PENDAHULUAN}

Pembelajaran diharapkan mengacu pada kompetensi dan mengoptimalkan peran siswa. Guru hanya sebagai fasilitator dalam membimbing dan mengarahkan siswa dalam proses pembelajaran, Tugas guru dalam rangka mengoptimalisasi proses belajar mengajar adalah sebagai fasilitator yang mampu mengembangkan kemauan belajar siswa, mengembangkan kondisi belajar yang relevan agar tercipta suasana belajar secara wajar dengan penuh kegembiraan. Oleh sebab itu agar dapat berhasil dengan baik, guru harus mampu melihat kemampuan siswanya dalam memahami materi. Untuk memahami materi pembelajaran diperlukan metode pembelajaran yang efektif.

Metode pembelajaran merupakan salah satu tehnik mengajar yang di lakukan guru untuk memotivasi cara belajar siswa. Selain itu metode pembelajaran adalah cara yang digunakan guru untuk menyampaikan pelajaran kepada siswa dan merupakan salah satu faktor atau komponen pendidikan yang sangat menentukan berhasil tidaknya suatu pembelajaran ( Hamdani, 2010: 80 ) Selanjutnya Percival, Elington 1984 (dalam Uno 2006:35) mengemukakan tujuan pembelajaran adalah suatu pernyataan yang jelas dan menunjukkan penampilan atau ketrampilan siswa tertentu yang diharapkan dapat dicapai sebagai hasil belajar. Dari kedua teori diatas dapat disimpulkan bahwa proses pembelajaran akan berhasil jika guru mampu menguasai dan menggunakan metode pembelajaran dengan baik dan benar. Suatu pembelajaran akan bisa disebut berhasil secara baik, manakala guru mampu mengubah pola pikir, pengetahuan, sifat dan karakter siswa, serta mampu menumbuh-kembangkan kesadaran siswa untuk belajar, sehingga pengalaman yang diperoleh peserta didik selama ia terlibat dalam proses pembelajaran dapat dirasakan manfaatnya secara langsung bagi perkembangan pribadinya.

Kunci pokok pembelajaran ada pada seorang guru. Tetapi ini bukan berarti proses pembelajaran hanya guru yang aktif, sedang peserta didik pasif. Pembelajaran menuntut keaktifan kedua pihak yang sama-sama menjadi subyek pembelajaran. Oleh karena itu seorang guru harus mampu menguasai segala bentuk pengajaran, sifat dan karakter serta kemampuan belajar setiap peserta didiknya. Menurut Grasser (dalam Uno 2014:157) guru harus menguasai 3 hal yakni : (1) kemampuan mendiagnosa tingkah laku siswa, (2) kemampuan melaksanakan proses pembelajaran, (3) kemampuan mengukur hasil belajar siswa. Aktivitas juga 
menekankan cara pendekatan sebuah kelompok terhadap masalah, solusi, serta lebih banyak menghasilkan banyak ide daripada hanya satu orang saja (Helen Dawn 2009:51)

Menulis puisi merupakan salah satu kegiatan yang sangat berhubungan erat dengan membaca. Hal ini tentu memerlukan suatu strategi penanaman keterampilan menulis setelah setiap orang mampu membaca. Oleh karena itu menulis dan membaca memiliki hubungan yang sangat erat. Dalam menulis sebuah puisi siswa harus benar-benar memahami apa makna dari puisi yang ditulisnya, guru harus mampu menberikan contoh terbaik dan mengajak seluruh siswa untuk dapat menciptakan dan membuat puisi sendiri tanpa bantuan guru sehingga kompetensi yang diharapkan dalam menulis puisi tercapai secara maksimal.

Namun pada kenyataannya, pembelajaran menulis puisi masih mengalami banyak kendala baik yang berasal dari guru maupun siswa. Kendala dari guru, di antaranya guru tidak dapat menentukan metode yang tepat dalam membelajarkan menulis puisi. Kendala dari siswa, sebagian besar siswa tidak memahami cara membuat puisi yang baik dan benar. Proses belajar mengajar di SDN 2 Limboto Kecamatan Limboto Kabupaten
Gorontalo, khususnya siswa kelas VI dalam pembelajaran menulis puisi juga belum sepenuhnya dilakukan dengan teknik yang baik. Kegagalan pembelajaran menulis puisi mencapai 37\%. Hal ini disebabkan oleh kurangnya kreativitas guru dalam pembelajaran menulis puisi, sehingga menyebabkan rendahnya kemampuan dan keterampilan siswa dalam menulis puisi yang baik dan benar. Apabila hal ini tidak segera diperbaiki, maka tujuan pembelajaran yang diharapkan tidak akan tercapai dengan baik. Oleh sebab itu perlu adanya suatu metode dalam membangkitkan motivasi dan semangat belajar siswa agar hasil belajar siswa menjadi baik, sebab guru di tuntut untuk kreatif dalam mencari metode pembelajaran untuk menarik perhatian siswa dalam belajar (Erwin Widiasworo, 2013: 61) pemilihan metode tentunya sangat bermanfaat bagi guru dan siswa, namun untuk lebih membuat siswa agar termotivasi dan bersemangat dalam belajar perlu pemilihan metode yang tepat, salah satu metode yang menjadi pilihan untuk meningkatkan hasil belajar siswa adalah metode imitasi, metode ini merupakan salah satu metode yang melibatkan guru secara langsung sebagai model untuk menunjukkan kepada siswa bagaimana cara menulis atau menyusun kata-kata sehingga 
menjadi satu kata atau rangkaian puisi yang baik dan benar. Jika hal ini terlaksana dengan baik dan benar maka yang menjadi salah satu tujuan dari kurikulum, yaitu siswa dapat menulis puisi dengan baik dan benar akan tercapai, dengan kata lain kompetensi dasar menulis puisi tuntas dan sesuai dengan KKM yang telah ditetapkan. Metode imitasi merupakan solusi untuk memberikan motivasi belajar menulis puisi pada siswa, hal ini di karenakan metode imitasi dapat melibatkan guru dan siswa secara langsung dalam menulis sebuah puisi.

\section{METODE}

Penelitian ini menggunakan jenis Penelitian Tindakan Kelas atau PTK. Penelitian tindakan kelas PTK atau Classroom Action Research ( CAR ) yang dilaksanakan oleh guru kelas merupakan tindakan-tindakan yang dilakukan secara siklus, dalam rangka memecahkan masalah sampai masalah itu terpecahkan (Yudistira, 2013: 24 ). Karakteristik Penelitian ini adalah siswa kelas VI SDN 2 Limboto Kabupaten Gorontalo, dengan jumlah siswa 33 orang. Penelitian ini terdiri atas dua siklus dengan prosedur penelitian mencakup tahapan perencanaan, pemantauan, tindakan, observasi, refleksi dan refleksi perencanaan. Adapun rancangan penelitian digambarkan pada bagan berikut ini.

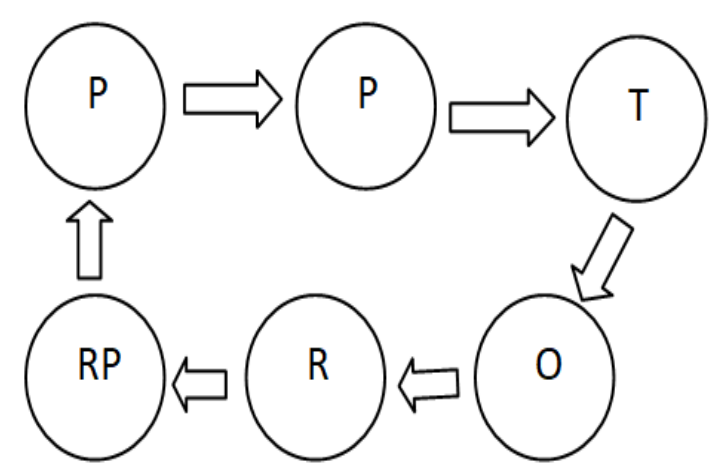

Gambar 1: Rancangan penelitian

Variabel yang di gunakan dalam penelitian ini terdiri atas dua variabel yaitu 1)Variabel pembelajaran menulis puisi dengan metode imitasi atau input ( masukan) yaitu pembelajaran dengan metode imitasi dimana guru memberikan contoh cara membuat puisi yang baik dan benar dan siswa meniru dengan memilih sendiri tema yang di sukai kemudian menulis puisi seperti yang di contohkan oleh guru. 2) variabel kemampuan siswa dalam menulis puisi output ( hasil) dengan metode imitasi yaitu kemampuan siswa dalam menulis puisi dengan penulisan yang baik dan benar dengan aspek penilain mencakup: 1) Kesesuain isi, 2) Pilihan kata, 3) Pengimajinasian, 4) Ritme / unsur bunyi. Tehnik pengumpulan data di lakukan dengan 2 cara yaitu: 1) Menggunakan Tes hasil kemampuan siswa dalam membuat puisi, 2) Menggunakan lembar observasi 


\section{HASIL DAN PEMBAHASAN}

Pelaksanaan pembelajaran dengan menggunakan metode imitasi di lakukan dalam 2 siklus, masing-masing siklus dilaksanakan dalam dua kali pertemuan. Setiap pertemuan berdasarkan pada rencana pelaksanaan pembelajaran (RPP) dan skenario pembelajaran. Pada pra pembelajaran kemampuan siswa dalam menulis puisi sangat rendah, hal ini terbukti dengan hasil yang di peroleh seperti pada tabel berikut ini:

Tabel. I

Kemampuan Siswa Menulis Puisi

\begin{tabular}{|l|c|c|}
\hline \multirow{2}{*}{ No } & \multicolumn{2}{|c|}{ Jumlah Siswa } \\
\cline { 2 - 3 } & $\begin{array}{c}\text { Mampu Membuat Puisi } \\
\text { dengan baik dan benar }\end{array}$ & $\begin{array}{c}\text { Kurang Mampu Membuat Puisi } \\
\text { dengan baik dan benar }\end{array}$ \\
\hline 1 & 4 & 29 \\
\hline$\%$ & $0,12 \%$ & $0,87 \%$ \\
\hline \multicolumn{2}{|c|}{ Prosentase } & $0,75 \%$ \\
\hline
\end{tabular}

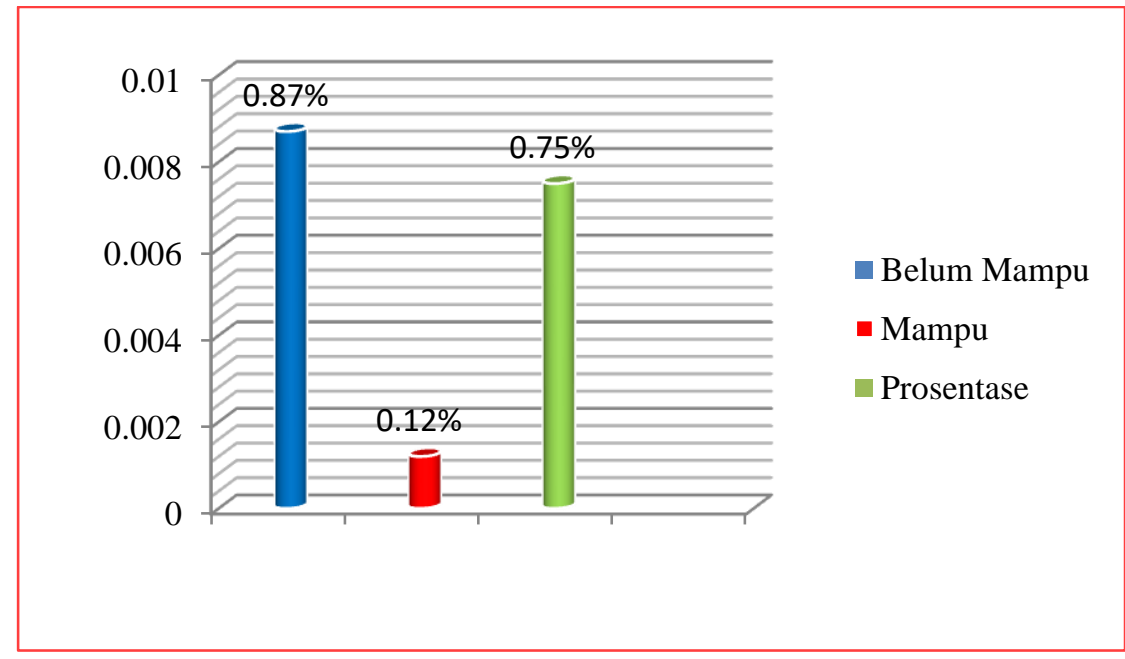

Gambar 1. Pra Siklus Kemampuan Siswa Dalam Menulis Puisi

Pada siklus I siswa yang mampu membuat puisi dengan baik dan benar hanya 13 orang atau $0,39 \%$. Sedangkan siswa yang kurang mampu membuat puisi dengan baik dan benar sebanyak 20 orang atau $0,60 \%$ dengan prosentase sebesar $0,21 \%$ seperti pada tabel berikut ini: 
Tabel. II

Siklus I Kemampuan Siswa Menulis Puisi

\begin{tabular}{|c|c|c|}
\hline \multirow[b]{2}{*}{ No } & \multicolumn{2}{|c|}{ Jumlah Siswa } \\
\hline & $\begin{array}{l}\text { Mampu Membuat Puisi } \\
\text { dengan baik dan benar }\end{array}$ & $\begin{array}{l}\text { Kurang Mampu Membuat Puisi } \\
\text { dengan baik dan benar }\end{array}$ \\
\hline 1 & 13 Siswa & 20 Siswa \\
\hline$\%$ & $0,39 \%$ & $0,60 \%$ \\
\hline & Prosentase & $0,21 \%$ \\
\hline
\end{tabular}

Dari jumlah siswa dan prosentase yang ada jelas terlihat bahwa kemampuan siswa dalam menulis puisi belum memenuhi standar yang telah di tetapkan oleh sekolah dan perlu tindakan lebih lanjut dari guru dengan memperbaiki penggunaan metode imitasi pada proses pembelajaran berikutnya.

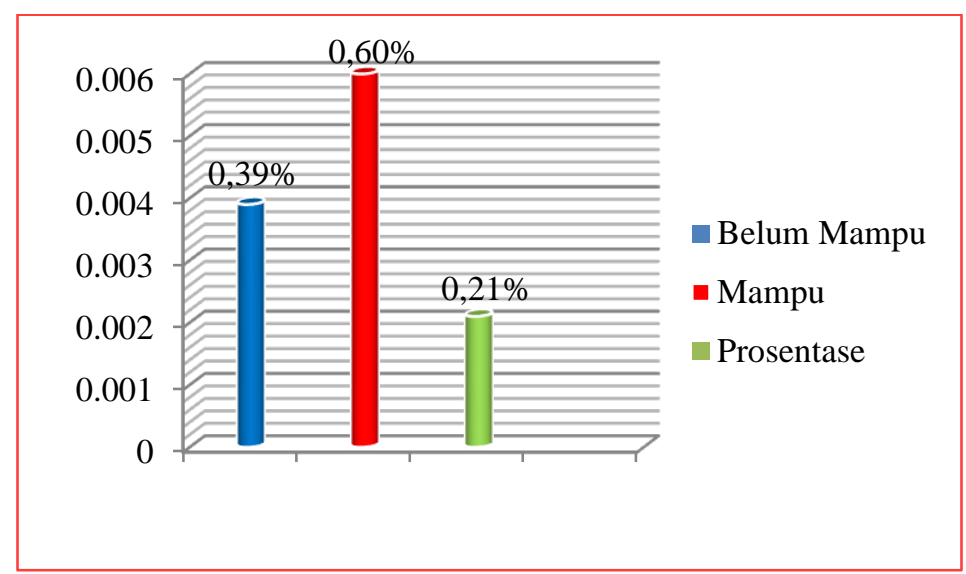

Gambar 2. Kemampuan Siswa Dalam Menulis Puisi ( Siklus I )

Namun peningkatan terjadi pada siklus II dari 33 orang siswa yang mampu membuat puisi sebanyak 28 dengan prosentase sebesar $0,85 \%$, dan yang kurang mampu sebanyak 5 orang siswa dengan prosentase sebesar $0,15 \%$. Prosentase dari keduannya sebesar $0,70 \%$. Peningkatan yang terjadi ini menunjukkan bahwa kemampuan siswa dalam menulis puisi telah mencapai standar ketuntasan minimal atau KKM yang telah di tetapkan oleh sekolah yaitu 
Tabel. II

Kemampuan Siswa Menulis Puisi ( Siklus II

\begin{tabular}{|c|c|c|}
\hline \multirow[b]{2}{*}{ No } & \multicolumn{2}{|c|}{ Jumlah Siswa } \\
\hline & $\begin{array}{l}\text { Mampu Membuat Puisi } \\
\text { dengan baik dan benar }\end{array}$ & $\begin{array}{l}\text { Kurang Mampu Membuat Puisi dengan } \\
\text { baik dan benar }\end{array}$ \\
\hline 1 & 28 Siswa & 5 Siswa \\
\hline$\%$ & $0,85 \%$ & $0,15 \%$ \\
\hline & Prosentase & $0,70 \%$ \\
\hline
\end{tabular}



Gambar 3. Kemampuan Siswa Dalam Menulis Puisi ( Siklus II

\section{KESIMPULAN}

Proses pembelajaran dengan menggunakan metode imitasi pada siklus I dan siklus II berlangsung dalam alur atau tahapan yang sama. Dimana pada pelaksanaan tiap siklus dilakukan refleksi untuk melihat kekurangan dari setiap siklus dengan penggunaan metode, Pada siklus I, siswa diberi pemahaman tentang cara menulis puisi yang baik dan benar dengan metode imitasi yaitu guru memperagakan atau memberikan contoh cara membuat atau menulis puisi berdasarkan tema atau media yang disiapkan, selebihnya siswa meniru dengan membuat sendiri puisi berdasarkan apa yang telah mereka amati dan lihat. Sedangkan pada siklus II, guru 
memberikan kebebasan kepada siswa untuk memilih tema dan membuat sendiri puisi berdasarkan contoh yang telah mereka buat pada siklus I. Pada siklus I sebagian besar siswa belum mampu membuat puisi dengan baik dan benar. Namun setelah di lakukan perbaikanperbaikan pada siklus II, peningkatan terjadi dengan sangat baik. Hal ini ditandai dengan perubahan perilaku dan kemampuan siswa dalam menulis puisi dengan baik dan benar

\section{DAFTAR PUSTAKA}

Alwasilah, A. Chaedar \& Furqanul Aziz. (1998). Pengajaran Bahasa Komunikatif, Teori dan Praktek.Bandung: Remaja Rosda Karya

Aryani. (2010). Strategi Pembelajaran Bahasa. Yogyakarta:Pustaka Insan Mandiri.

Badrun, A. (1989). Teori Puisi. Jakarta: Depdikbud.

Harun, H. (2018). Penggunaan metode tutor orsi dalam meningkatkan hasil belajar matematika di kelas V SDN 2 Limboto Kabupaten Gorontalo

Hamdani. (2010). Strategi Belajar Mengajar. Bandung: CV. Alfabeta

Retno Sapto. (2011). Penerapan Metode Pembelajaran Tutor Sebaya Untuk Meningkatkan Hasil Belajar Menggambar Busana di SMK
Ma'Arif 2 Sleman. Tehnik. Yokyakarta.

Santosa, P. (2004). Materi dan Pembelajaranan Bahasa Indonesia SD. Jakarta: Universitas Terbuka

Tarigan H.G. (2000).Sastra Anak. Jakarta

Hamzah.U. (2006). Perencanaan Pembelajaran. Jakarta: PT. Bumi Aksara.

Hamzah, U. \& Rauf, A. (2008). Desain Pembelajaran. Gorontalo: BMT. Nurul Janah. 